\title{
Periprosthetic joint infection after total knee arthroplasty: a bibliometrics analysis
}

\author{
Songpo Shen", Yichao Zhang", Qiang Zhang, Kai Xiao, Jiaguang Tang \\ Department of Orthopedic Surgery, Beijing Tongren Hospital, Capital Medical University, Beijing, China \\ Contributions: (I) Conception and design: S Shen, Y Zhang; (II) Administrative support: Q Zhang; (III) Provision of study materials or patients: K \\ Xiao; (IV) Collection and assembly of data: S Shen, Y Zhang, J Tang; (V) Data analysis and interpretation: S Shen, Y Zhang; (VI) Manuscript writing: \\ All authors; (VII) Final approval of manuscript: All authors. \\ \#These authors contributed equally to this work. \\ Correspondence to: Jiaguang Tang. Department of Orthopedic Surgery, Beijing Tongren Hospital, Capital Medical University, Beijing 100730, China. \\ Email: tangjiaguang2013@163.com.
}

Background: Total knee arthroplasty (TKA) has brought hope to patients with malignant knee joint diseases. Infection is one of the serious complications after TKA, and the purpose of this study was to use bibliometrics to analyze the current research status of infection after this surgery, to unmask any deficiencies with current research, and to provide references for future researchers.

Methods: We used the Science Citation Index Expanded (SCI-E) database in the Web of Science Core Collection (WOSCC) as the data source, using the search terms "total knee arthroplasty" and "infection" respectively. The "And" operation was performed on the search results of the two subject terms, and the intersection of the two search results was taken as the final search result. CiteSpace software was used to analyze the results.

Results: The search results consisted of 5,600 documents, with a total citation frequency of 148,871. The average number of citations for each literature was 26.58 , and the h-index was 142 . The top five countries in the number of publications were the United States, China, Germany, the United Kingdom, and Spain, while the top five centrally ranked countries were the United States, the Netherlands, Germany, the United Kingdom, and France. The top five institutions with the number of publications were Thomas Jefferson Univ, Mayo Clin, Hosp Special Surg, Rush Univ, and Cleveland Clin, while the top institutions for centrality were Thomas Jefferson Univ, Tel Aviv Univ, Univ Melbourne, and Rush Univ. The top five authors of the number of published articles were Parvizi J, Mont MA, Valle CJD, Chen AF, and Hanssen AD, and the top three authors for centrality were Parvizi J, Mont MA, and Valle CJD. The main journals were 7 Bone foint Surg Am, Clin Orthop Relat R, 7 Arthroplasty, 7 Bone foint Surg Br, and Int Orthop, and the top five keywords used were total knee arthroplasty, total hip arthroplasty, replacement, infection, and arthroplasty.

Conclusions: There is a lack of studies with high-level evidence. The focus of related research in recent years has not changed significantly. More randomized controlled studies are required to provide evidence-based medicine.

Keywords: Total knee arthroplasty (TKA); infection; prevention; management; bibliometrics analysis

Submitted Jul 23, 2021. Accepted for publication Sep 10, 2021.

doi: 10.21037/apm-21-2278

View this article at: https://dx.doi.org/10.21037/apm-21-2278 


\section{Introduction}

The development and improvement of total knee arthroplasty (TKA) has brought hope to patients with malignant knee joint diseases. TKA can effectively help patients relieve pain, facilitate the reconstruction of knee joint function, and is of great significance for improving the prognosis of patients (1). However, with the widespread development of TKA, the incidence of postoperative complications including infection, has also increased (2). The incidence of infection after TKA in foreign countries has dropped from $1-23 \%$ when the operation was first performed, to $0.8-1.9 \%$ at present $(3,4)$, while in China this figure remains relatively high, at $15 \%$. According to the scope of involvement, infection after TKA is divided into superficial infection (not involving the joint capsule) and deep infection (involving the joint capsule), and according to the onset and course of the disease, it is divided into acute or early onset infection (within 2 weeks after TKA) and chronic or delayed infection (2 weeks after TKA). Many factors are associated with infection after TKA, including obesity, diabetes, rheumatic arthritis, cancer, malnutrition, underlying diseases (systematic or local infection, heart diseases, renal diseases, etc.) and no antibiotic prophylaxis (2).

Infections after TKA are usually early and superficial. However, failure to control an infection in a timely manner may result in pathogenic bacteria multiplying and invading the knee prosthesis through blood-borne pathways, inducing new serious infections and causing damage to the prosthesis. In severe cases, disastrous consequences to joint function may occur, further increasing patient suffering, prolonging the postoperative and rehabilitation hospital stay and likelihood of subsequent hospitalizations, raising costs, and attracting the likelihood of long-term antibiotic therapy $(5,6)$. In view of this, the identification of highrisk factors that induce infection after TKA and measures which can guide effective pre-operative, perioperative, and postoperative control are particularly important to physicians (1,7-9), and many studies on the topic have been published. The main treatments for infection after TKA include antibiotic therapy, debridement, insertion of another prothesis and knee arthrodesis and amputation $(2,7)$. Bibliometrics involves searching literature on a subject and identifying its current status, development trends, and leading research institutions and researchers. It also provides a macro view for future research and reference to assist the choice of research directions, and avoid duplication and omission of important research targets (10). In a previous study, Li et al conducted a global bibliometric analysis from meta-analysis studies to estimate global PJI research (11). The authors found that the main topics on periprosthetic joint infection were alpha-defensin, antibiotic use, risk factors of intra-articular steroid injections, and the location of prosthetic hip and knee infection (11). The purpose of this study was to use bibliometrics to analyze the current research status of infection after TKA and to identify possible references for future investigations based on all kinds of related literatures about infection after TKA.

\section{Methods}

\section{Data source}

The Web of Science Core Collection (WOSCC) Science Citation Index Expanded (SCI-E) database was used as the data source, and the publication time of the documents was from inception to (July 6, 2021).

\section{Retrieval strategy}

Subject term retrieval with the terms "total knee arthroplasty" and "infection" was used. The "And" operation was performed on the search results of the two subject terms, and the intersection of the two search results was taken as the final search result. The final search result and cited record were then exported in plain text format to form the original data set for the next analysis.

\section{Statistical analysis}

Data is expressed in quantity and percentage, and as no statistical comparison and correlation analysis were performed, no $\mathrm{P}$ value was set. CiteSpace software was used to analyze the original search results data set, and the content of the analysis included the annual change of the number of publications, the annual change of the number of citations of these publications, the distribution of countries/ institutions and journals, the distribution of authors, the use of keywords, and cooperation between countries, institutions, and authors. According to the analysis results, co-occurrence diagrams among countries, institutions, authors, and keywords were drawn to reflect the research status of infection after TKA. 
Table 1 Document type analysis of search results

\begin{tabular}{lcc}
\hline Document types & Records & \% of $\mathrm{n}=5,600$ \\
\hline Original article & 4,933 & 88.09 \\
Review & 541 & 9.66 \\
Proceedings paper & 308 & 5.50 \\
Early access & 64 & 1.14 \\
Editorial material & 62 & 1.11 \\
Letter & 32 & 0.57 \\
Meeting abstract & 23 & 0.41 \\
Correction & 5 & 0.09 \\
Book chapter & 4 & 0.07 \\
Note & 2 & 0.04 \\
Book review & 1 & 0.02 \\
Discussion & 1 & 0.02 \\
Retracted publication & 1 & 0.02 \\
\hline
\end{tabular}

\section{Results}

\section{Basic information}

Preliminary search results revealed a total of 5,977 related research literature records, of which 377 duplicates were excluded. Of the remaining 5,600 publications, 4,933 were original articles, 541 reviews, 308 proceedings papers, and 64 were early access articles. There were 62 editorial materials, 32 letters, 23 meeting abstracts, five corrections, four book chapters, two notes, one book review, one discussion, and one retracted publication (Tables 1,2, Figure 1). From the perspective of the publication time and quantity of the literature, the research on this subject has received extensive attention for a long duration, and related research is generally increasing year by year. The citation frequency of documents totaled 148,871 , while the average citation frequency of each document was 26.58 , and h-index (which is an index reflecting the influence of a specific author or article, the higher h-index, the higher influence) was 142 (Figure 2). The citation frequency of documents also showed an obvious increasing trend.

\section{Distribution of countries and institutions}

CiteSpace V software was used to analyze the distribution of countries and institutions of document sources. The national visualization map (Figure 3) shows $\mathrm{N}=106$ and
Table 2 Annual changes in the number of papers

\begin{tabular}{|c|c|c|}
\hline Year & Records & $\%$ of 5,600 \\
\hline 2021 & 290 & 5.18 \\
\hline 2020 & 619 & 11.05 \\
\hline 2019 & 525 & 9.38 \\
\hline 2018 & 485 & 8.66 \\
\hline 2017 & 479 & 8.55 \\
\hline 2016 & 437 & 7.80 \\
\hline 2015 & 351 & 6.27 \\
\hline 2014 & 331 & 5.91 \\
\hline 2013 & 257 & 4.59 \\
\hline 2012 & 235 & 4.20 \\
\hline 2011 & 192 & 3.43 \\
\hline 2010 & 177 & 3.16 \\
\hline 2009 & 145 & 2.59 \\
\hline 2008 & 123 & 2.20 \\
\hline 2007 & 130 & 2.32 \\
\hline 2006 & 125 & 2.23 \\
\hline 2005 & 99 & 1.77 \\
\hline 2004 & 87 & 1.55 \\
\hline 2003 & 79 & 1.41 \\
\hline 2002 & 56 & 1.00 \\
\hline 2001 & 67 & 1.20 \\
\hline 2000 & 42 & 0.75 \\
\hline 1999 & 36 & 0.64 \\
\hline 1998 & 35 & 0.63 \\
\hline 1997 & 35 & 0.63 \\
\hline 1996 & 36 & 0.64 \\
\hline 1995 & 36 & 0.64 \\
\hline 1994 & 23 & 0.41 \\
\hline 1993 & 22 & 0.39 \\
\hline 1992 & 12 & 0.21 \\
\hline 1991 & 23 & 0.41 \\
\hline 1990 & 4 & 0.07 \\
\hline 1988 & 2 & 0.04 \\
\hline 1987 & 1 & 0.02 \\
\hline 1985 & 1 & 0.02 \\
\hline 1983 & 1 & 0.02 \\
\hline 1977 & 1 & 0.02 \\
\hline 1975 & 1 & 0.02 \\
\hline
\end{tabular}




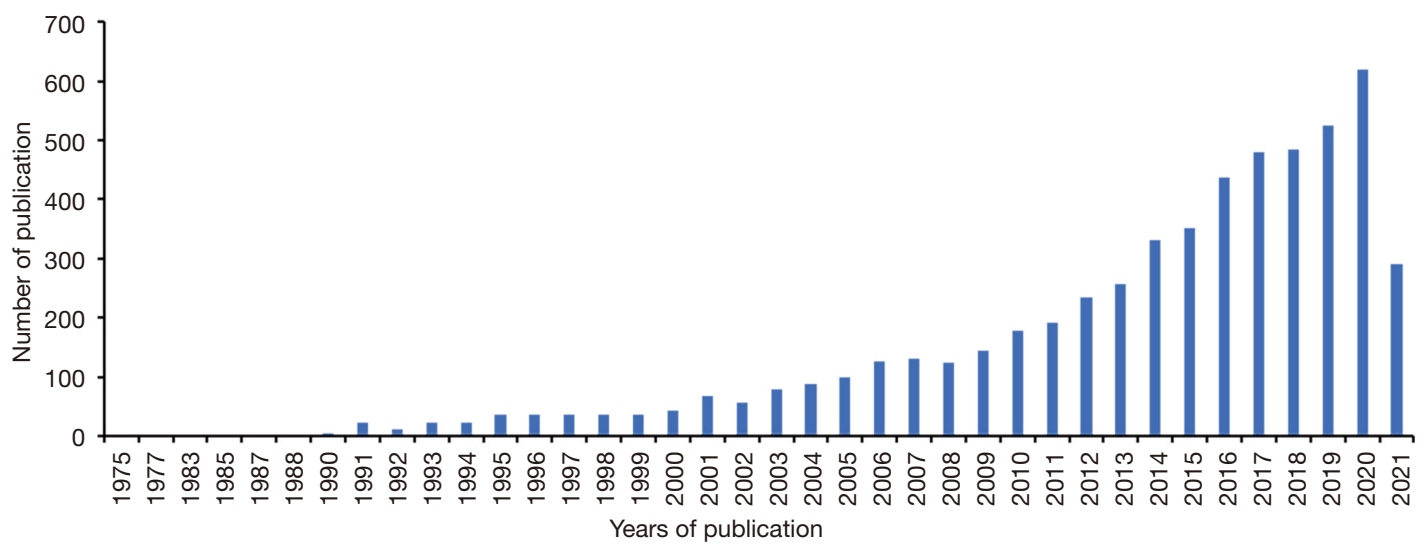

Figure 1 Trends in the number of annual papers published.

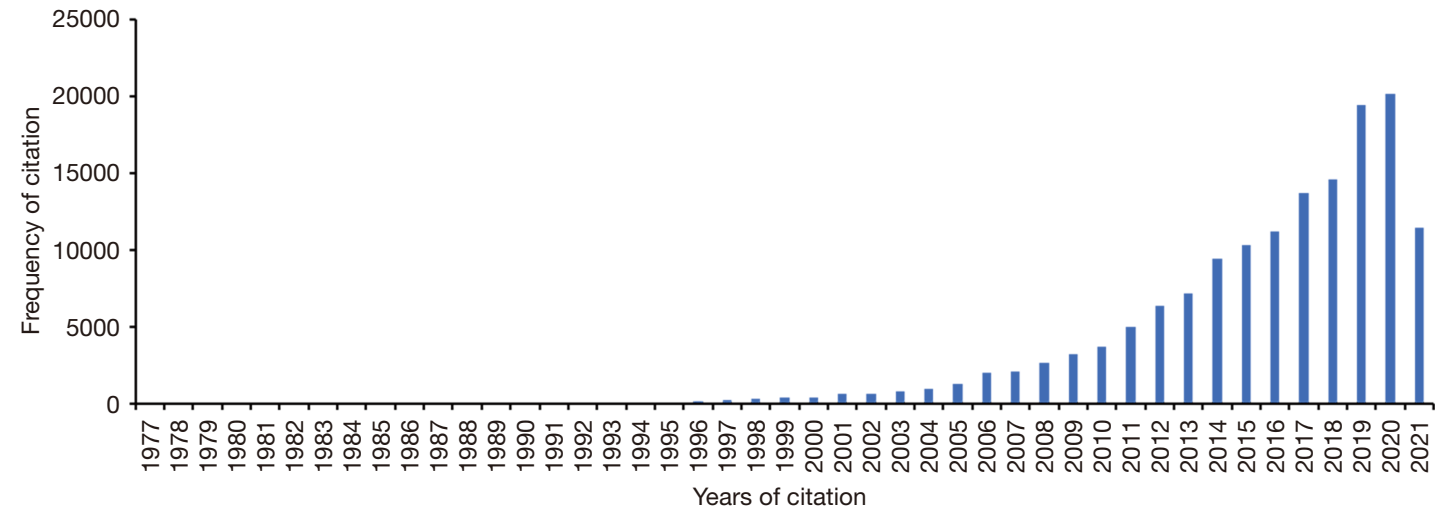

Figure 2 Annual trend of the number of documents cited.

$\mathrm{E}=436$, where $\mathrm{N}$ represents the number of network nodes, and one node represents one country or region, E represents the number of connections, and one connection represents two countries appearing together in one document. This shows there are many countries participating in research in this field. The organization visualization map (Figure 4) shows $\mathrm{N}=884$ and $\mathrm{E}=1508$, where $\mathrm{N}$ represents the number of institutions, and $\mathrm{E}$ represents the relationship between institutions, that is, each link represents the institutions at both ends of the link appearing in one document at the same time. This shows many institutions have carried out research in this field. The top five countries with the highest number of publications were the United States, China, Germany, the United Kingdom, and Spain, while the top five with centrality were the United States, the Netherlands, Germany, the United Kingdom, and France (Tables 3 and 4). The top five institutions with the highest number of publications were Thomas Jefferson Univ, Mayo Clin, Hosp Special Surg, Rush Univ, and Cleveland Clin (Table 5), while the top for centrality were Thomas Jefferson Univ, Tel Aviv Univ, Univ Melbourne, and Rush Univ (Table 6).

\section{Autbors analysis}

The top five authors of the number of published documents were (regardless of the order of the signature of the author): Parvizi J, Mont MA, Valle CJD, Chen AF, and Hanssen $\mathrm{AD}$ (Table 7), and for centrality, the top three authors were Parvizi J, Mont MA, and Valle CJD (Figure 5, Table 8). The top five authors of co-cited records were Parvizi J, Kurtz SM, Bozic KJ, Kurtz S, and Insall JN, and there were 10 authors with co-cited centrality scores above 0.03 (Figure 6, Tables 9,10). 
Figure 3 National visualization map.

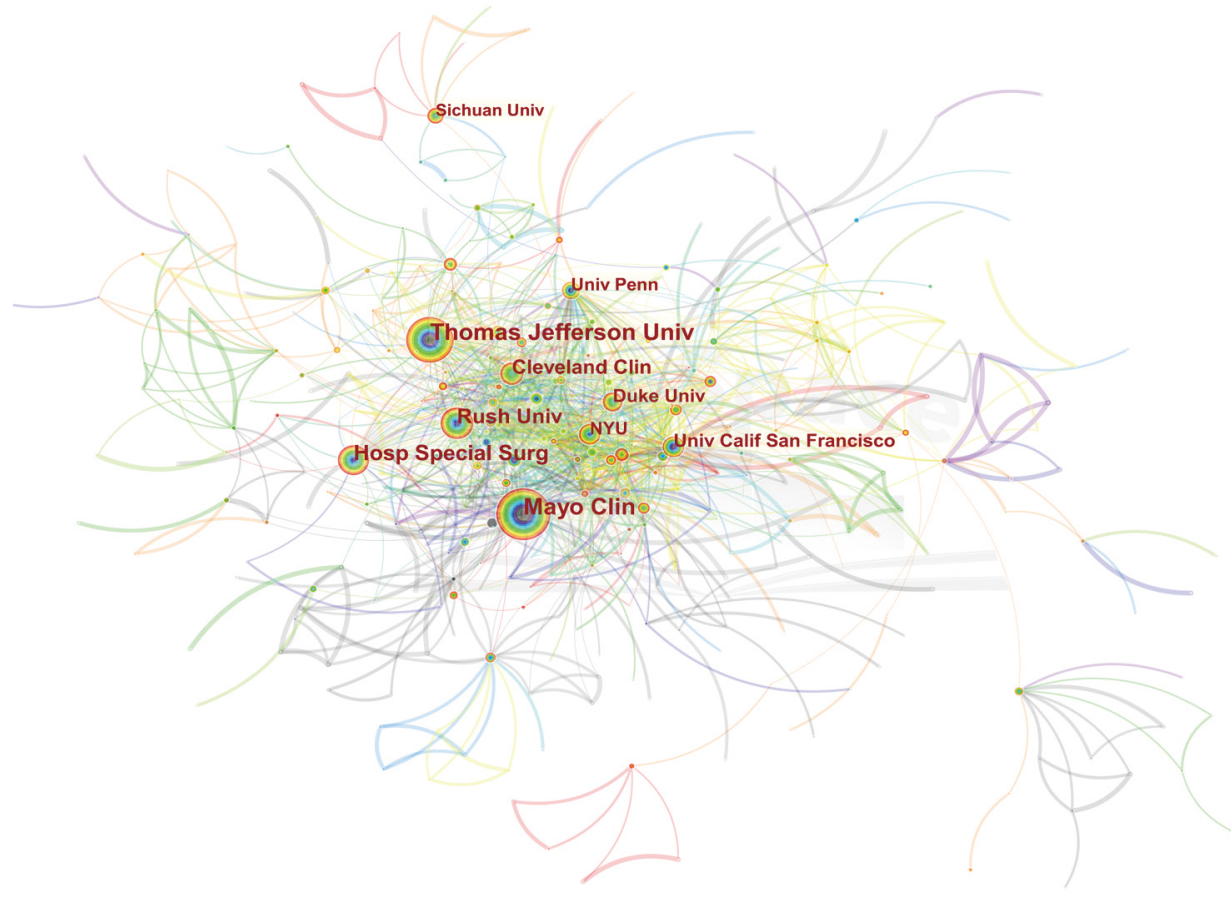

Figure 4 Visualization map of institutions. 
Table 3 Top 10 countries for number of papers published

\begin{tabular}{lcc}
\hline Rank & Countries & Records \\
\hline 1 & The United States & 2,423 \\
2 & China & 517 \\
3 & Germany & 491 \\
4 & England & 390 \\
5 & Spain & 180 \\
6 & Canada & 178 \\
7 & France & 169 \\
8 & Italy & 151 \\
9 & Netherlands & 135 \\
10 & Australia & 134 \\
\hline
\end{tabular}

Table 4 Top 10 countries for centrality

\begin{tabular}{lcc}
\hline Rank & Countries & Centrality \\
\hline 1 & The United States & 0.60 \\
2 & Netherlands & 0.21 \\
3 & Germany & 0.18 \\
4 & England & 0.15 \\
5 & France & 0.14 \\
6 & China & 0.10 \\
7 & Italy & 0.10 \\
8 & Spain & 0.07 \\
9 & Canada & 0.07 \\
10 & South Korea & 0.07 \\
\hline
\end{tabular}

Table 5 Top 10 institutions in the number of papers published

\begin{tabular}{lcc}
\hline Rank & Institutions & Records \\
\hline 1 & Thomas Jefferson Univ & 243 \\
2 & Mayo Clin & 216 \\
3 & Hosp Special Surg & 138 \\
4 & Rush Univ & 114 \\
5 & Cleveland Clin & 103 \\
6 & Duke Univ & 73 \\
7 & Univ Calif San Francisco & 71 \\
8 & New York University & 60 \\
9 & Univ Penn & 54 \\
10 & Sichuan Univ & 46 \\
\hline
\end{tabular}

Table 6 Top 10 institutions for centrality

\begin{tabular}{lcc}
\hline Rank & Institution & Centrality \\
\hline 1 & Thomas Jefferson Univ & 0.07 \\
2 & Tel Aviv Univ & 0.05 \\
3 & Univ Melbourne & 0.04 \\
4 & Rush Univ & 0.04 \\
5 & Charite Univ Med Berlin & 0.03 \\
6 & Univ Penn & 0.03 \\
7 & Cleveland Clin & 0.03 \\
8 & Hosp Special Surg & 0.03 \\
9 & Mayo Clin & 0.03 \\
10 & Univ Helsinki & 0.02 \\
\hline
\end{tabular}

Table 7 Top 10 authors of papers published

\begin{tabular}{lcc}
\hline Rank & Authors & Records \\
\hline 1 & Parvizi J & 198 \\
2 & Mont MA & 96 \\
3 & Valle CJD & 67 \\
4 & Chen AF & 59 \\
5 & Hanssen AD & 55 \\
6 & Higuera CA & 51 \\
7 & Abdel MP & 45 \\
8 & Berry DJ & 44 \\
9 & Schwarzkopf R & 42 \\
10 & Tan TL & 41 \\
\hline
\end{tabular}

\section{Fournal distribution}

The 5,600 articles in the search results were from 596 journals and among them, 11 journals had more than 100 articles (Table 11) and published 2,907 articles, accounting for 51.91\% of the total number of articles (Table 11). The top five journals cited by frequency were 7 Bone foint Surg Am, Clin Orthop Relat $R, \mathcal{F}$ Arthroplasty, $\mathcal{F}$ Bone Foint Surg Br, and Int Orthop (Table 12), and the top three journals with centrality scores were Arthritis Rheum, Ann Intern Med, and Am 7 Surg (the other seven journals in the top 10 journals all had a centrality score of 0.03 , Table 13 ).

\section{Keyword analysis}

CiteSpace V software was used to analyze the use of 


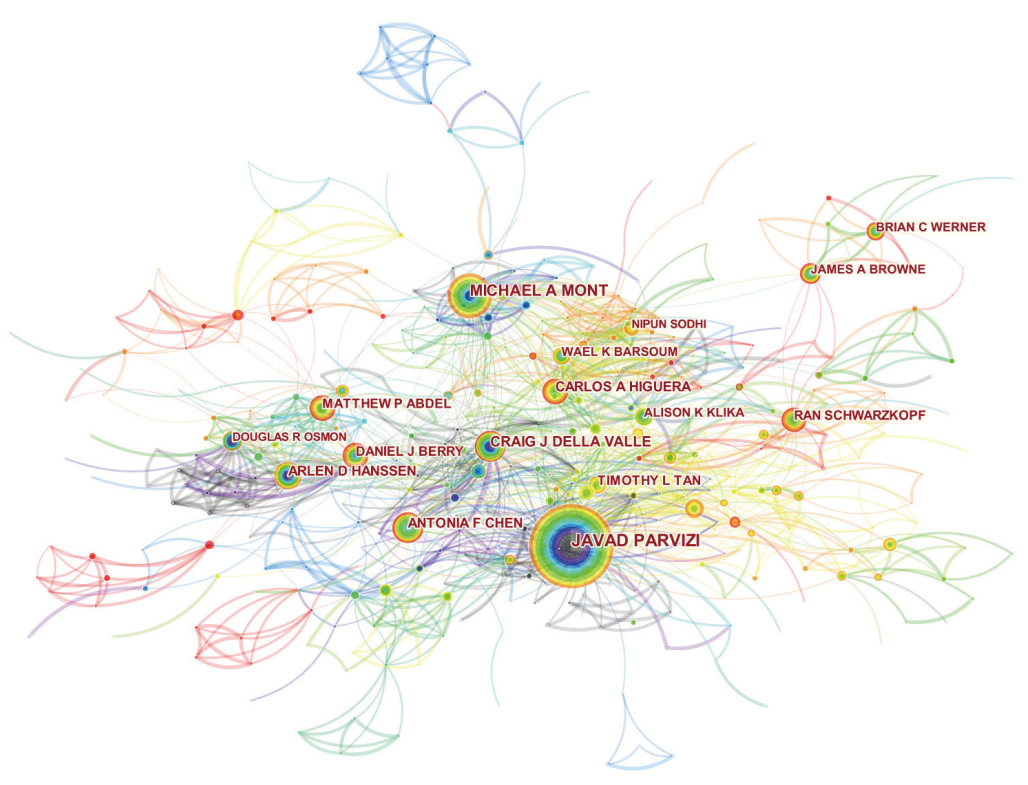

Figure 5 Visualization map of authors co-authored.

Table 8 Top 10 authors for centrality

\begin{tabular}{lcc}
\hline Rank & Authors & Centrality \\
\hline 1 & Parvizi J & 0.07 \\
2 & Mont MA & 0.05 \\
3 & Valle CJD & 0.05 \\
4 & Chen AF & 0.02 \\
5 & Abdel MP & 0.02 \\
6 & Browne JA & 0.02 \\
7 & Hanssen AD & 0.01 \\
8 & Higuera CA & 0.01 \\
9 & Berry DJ & 0.01 \\
10 & Schwarzkopf R & 0.01 \\
\hline
\end{tabular}

keywords and draw a keyword co-occurrence map (Figure 7), where $\mathrm{N}=730$, that is, a total of 730 keywords were used in these documents and $\mathrm{E}=7,088$, that is, the frequency of these keywords pairwise appearing in the literature at the same time was 7,088 times. The top five keywords used were total knee arthroplasty, total hip arthroplasty, replacement, infection, and arthroplasty (Table 14), and the top five keywords in the centrality score were total knee arthroplasty, infection, total hip arthroplasty, replacement, and prosthesis (Table 15). We further used CiteSpace to perform Burst detection on keywords with high frequency of use, and the results show that in recent years, relevant research on rehospitalization for renovation has attracted more attention (Figure 8).

\section{Discussion}

In this study, 5,600 publications on infection after TKA were retrieved from the SCI-E database using subject terms, and the analysis revealed the topic has been receiving extensive attention, with research literature and citation records showing an increasing trend over time. While most countries have conducted related research, the main countries doing so are the United States, Germany, the United Kingdom, and the Netherlands, and the proportion of international cooperative research is also relatively high. The main research institutions are also based in these countries, with the most prolific being Thomas Jefferson Univ in the United States. Authors who have published more documents and cooperated most are also from these major institutions and countries. Keyword analysis results showed that the current second revision after knee arthroplasty is the focus of research.

Osteoarthritis is a degenerative disease which usually occurs in weight-bearing joints with ageing, and the number of knee osteoarthritis patients is increasing over time due $(12,13)$. One major reason for this relates to our 


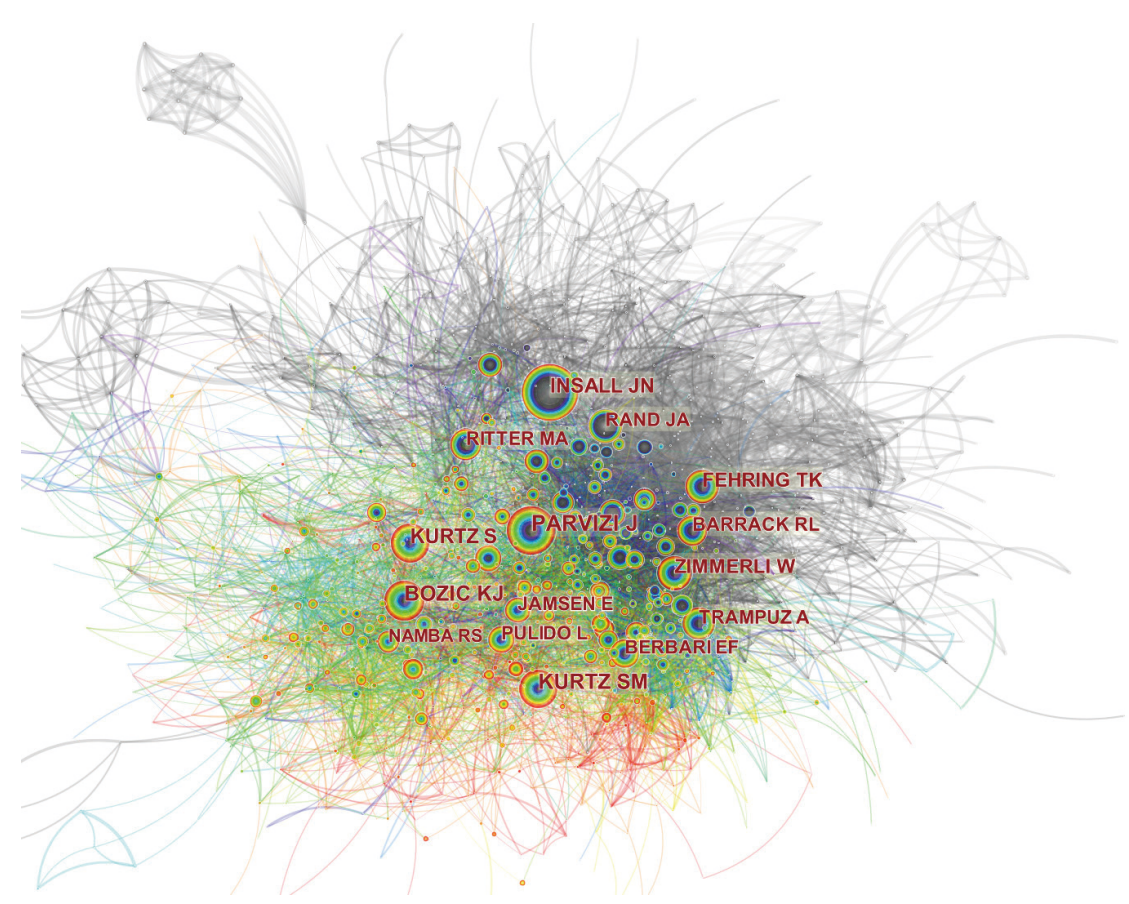

Figure 6 Visualization map of authors co-cited.

Table 9 Top 10 co-cited authors

\begin{tabular}{lcc}
\hline Rank & Authors & Frequency \\
\hline 1 & Parvizi J & 1,323 \\
2 & Kurtz SM & 947 \\
3 & Bozic KJ & 842 \\
4 & Kurtz S & 807 \\
5 & Insall JN & 728 \\
6 & Zimmerli W & 537 \\
7 & Fehring TK & 463 \\
8 & Trampuz A & 404 \\
9 & Jamsen E & 403 \\
10 & Rand JA & 390 \\
\hline
\end{tabular}

aging society, with prolonged life expectancy driving the number of patients with degenerative disease higher, and a second results from improvements in material living conditions worldwide, which has caused the number of obese patients to rise rapidly $(1,14)$. TKA can effectively improve knee joint function and relieve pain (1), and with advances in total knee replacement technology and the continuous improvement of materials, more patients are
Table 10 Top 10 co-cited authors for centrality

\begin{tabular}{lcc}
\hline Rank & Authors & Centrality \\
\hline 1 & Buchholz HW & 0.07 \\
2 & Barrack RL & 0.05 \\
3 & Insall JN & 0.04 \\
4 & Fehring TK & 0.04 \\
5 & Whiteside LA & 0.04 \\
6 & Charnley J & 0.04 \\
7 & Fitzgerald RH & 0.04 \\
8 & Lidwell OM & 0.04 \\
9 & Friedman RJ & 0.04 \\
10 & Bozic KJ & 0.03 \\
\hline
\end{tabular}

receiving this treatment. However, postoperative local infection has always troubled clinicians and patients (9), and much research is undertaken to both relieve and prevent this. The prevention of infection is generally divided into three stages: preoperative, intraoperative, and postoperative. Many studies conclude the nutritional status of the patient and blood glucose level should be carefully evaluated (15-17), and some have also found that when the 
Table 11 Top 11 journals in number of papers published

\begin{tabular}{lcc}
\hline Journals & Records & $\%$ of 5,600 \\
\hline Journal of Arthroplasty & 1,151 & 20.55 \\
Clinical Orthopaedics and Related Research & 419 & 7.48 \\
Journal of Bone and Joint Surgery American Volume & 337 & 2.02 \\
Bone Joint Journal & 164 & 2.93 \\
Knee & 147 & 2.46 \\
International Orthopaedics & 138 & 2.27 \\
Knee Surgery Sports Traumatology Arthroscopy & 127 & 1.95 \\
Orthopedics & 109 & 1.91 \\
Archives of Orthopaedic and Trauma Surgery & 107 & 1.88 \\
Journal of Bone and Joint Surgery British Volume & 105 & 1.84 \\
Journal of Knee Surgery & 103 & \\
\hline
\end{tabular}

Table 12 Top 10 journals cited

\begin{tabular}{lcc}
\hline Rank & Journals & Frequency \\
\hline 1 & J Bone Joint Surg Am & 4,796 \\
2 & Clin Orthop Relat $R$ & 4,753 \\
3 & J Arthroplasty & 4,575 \\
4 & J Bone Joint Surg Br & 3,326 \\
5 & Int Orthop & 1,738 \\
6 & Acta Orthop & 1,446 \\
7 & Orthopedics & 1,418 \\
8 & New Engl J Med & 1,325 \\
9 & Clin Infect Dis & 1,324 \\
10 & Bone Joint J & 1,244 \\
\hline
\end{tabular}

level of glycosylated hemoglobin is higher than 7.5 (14) or 7.7 (16), the risk of postoperative infection is significantly increased. Golladay et. al recommended the nutritional status of patients be evaluated before joint replacement surgery, including indicators such as serum albumin level, lymphocyte count, and transferrin level (17). During the operation, strict disinfection should be performed on the skin of the surgical area $(18,19)$, and the addition of disinfection records can also reduce the risk of infection $(20,21)$. There are many studies on the use of antibiotics for preventive treatment during the perioperative period, but the optimal plan requires further study. A metaanalysis of 26 studies (11,343 patients) indicated that
Table 13 Top 10 journals for centrality

\begin{tabular}{lcc}
\hline Rank & Journals & Centrality \\
\hline 1 & Arthritis Rheum & 0.07 \\
2 & Ann Intern Med & 0.04 \\
3 & Am J Surg & 0.04 \\
4 & Am J Infect Control & 0.03 \\
5 & Brit Med J & 0.03 \\
6 & Arch Surg-Chicago & 0.03 \\
7 & Arch Intern Med & 0.03 \\
8 & Brit J Surg & 0.03 \\
9 & Am J Roentgenol & 0.03 \\
10 & Am J Epidemiol & 0.03 \\
\hline
\end{tabular}

prophylactic antibiotics can reduce the absolute risk of wound infection by $8 \%$ and the relative risk by $81 \%(22)$. A systematic review and meta-analysis in 2019 included 23 RCTs, two prospective cohort studies, three retrospective cohort studies, and four case-control studies, enrolling a total of 51,627 patients, with the results confirming the benefits of surgical antibiotic prophylaxis (SAP) in total joint replacement surgery, although the continued use or use for more than 24 hours after surgery did not increase the benefits. However, some authors have also pointed out that the current available evidence is weak, and more research is required (23). Other studies have conducted indepth discussions on measures to prevent infection during 


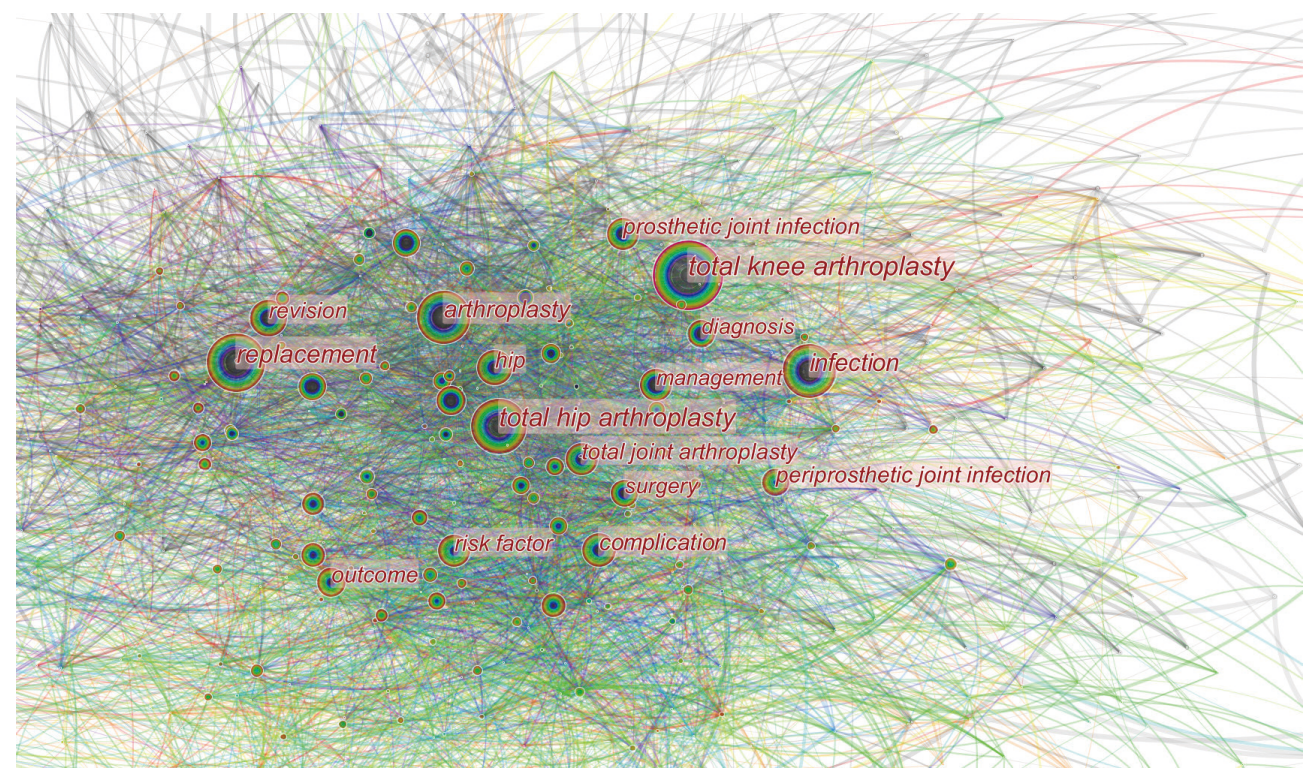

Figure 7 Keyword co-occurrence map.

Table 14 Top 10 keywords by frequency

\begin{tabular}{lcc}
\hline Rank & Keywords & Frequency \\
\hline 1 & Total knee arthroplasty & 2,895 \\
2 & Total hip arthroplasty & 1,863 \\
3 & Replacement & 1,484 \\
4 & Infection & 1,289 \\
5 & Arthroplasty & 1,062 \\
6 & Complication & 695 \\
7 & Hip & 663 \\
8 & Risk factor & 638 \\
9 & Outcome & 630 \\
10 & Periprosthetic joint infection & 595 \\
\hline
\end{tabular}

the perioperative period, but many have offered different results, and there is no mature regimen to recommend (4).

The treatment of infection after TKA mainly includes anti-infective treatment and surgical treatment (8). Antiinfective treatment should be based on the results of drug susceptibility tests, patient tolerance, and drug side effects to choose a personalized therapy (24). According to different infection stages and surgical treatment options, the treatment time of anti-infection agents is also different (25). The 2018 International Infection Consensus recommends that antibiotics for prosthesis-sparing debridement should
Table 15 Top 10 keywords of centrality

\begin{tabular}{lcc}
\hline Rank & Keywords & Centrality \\
\hline 1 & Total knee arthroplasty & 0.15 \\
2 & Infection & 0.08 \\
3 & Total hip arthroplasty & 0.07 \\
4 & Replacement & 0.07 \\
5 & Prosthesis & 0.07 \\
6 & Arthroplasty & 0.06 \\
7 & Total joint arthroplasty & 0.05 \\
8 & Diagnosis & 0.05 \\
9 & Complication & 0.04 \\
10 & Prevention & 0.04 \\
\hline
\end{tabular}

be used for no less than 6 weeks during the acute infection period (7), and for methicillin-resistant Staphylococcus aureus (MRSA), parenteral antibiotics and oral rifampicin should be used for 1 to 6 weeks, followed by oral rifampicin and highly bioactive drugs for 3 months (7). Patients with acute dry containment infections with gram-negative bacteria should also receive 6 to 12 weeks of antibiotic treatment according to the type of microorganisms $(7,26)$. In addition, the consensus also recommends that in the treatment of tuberculosis infection physicians must cooperate with infectious disease experts to choose 
Top 25 Keywords with the Strongest Citation Bursts

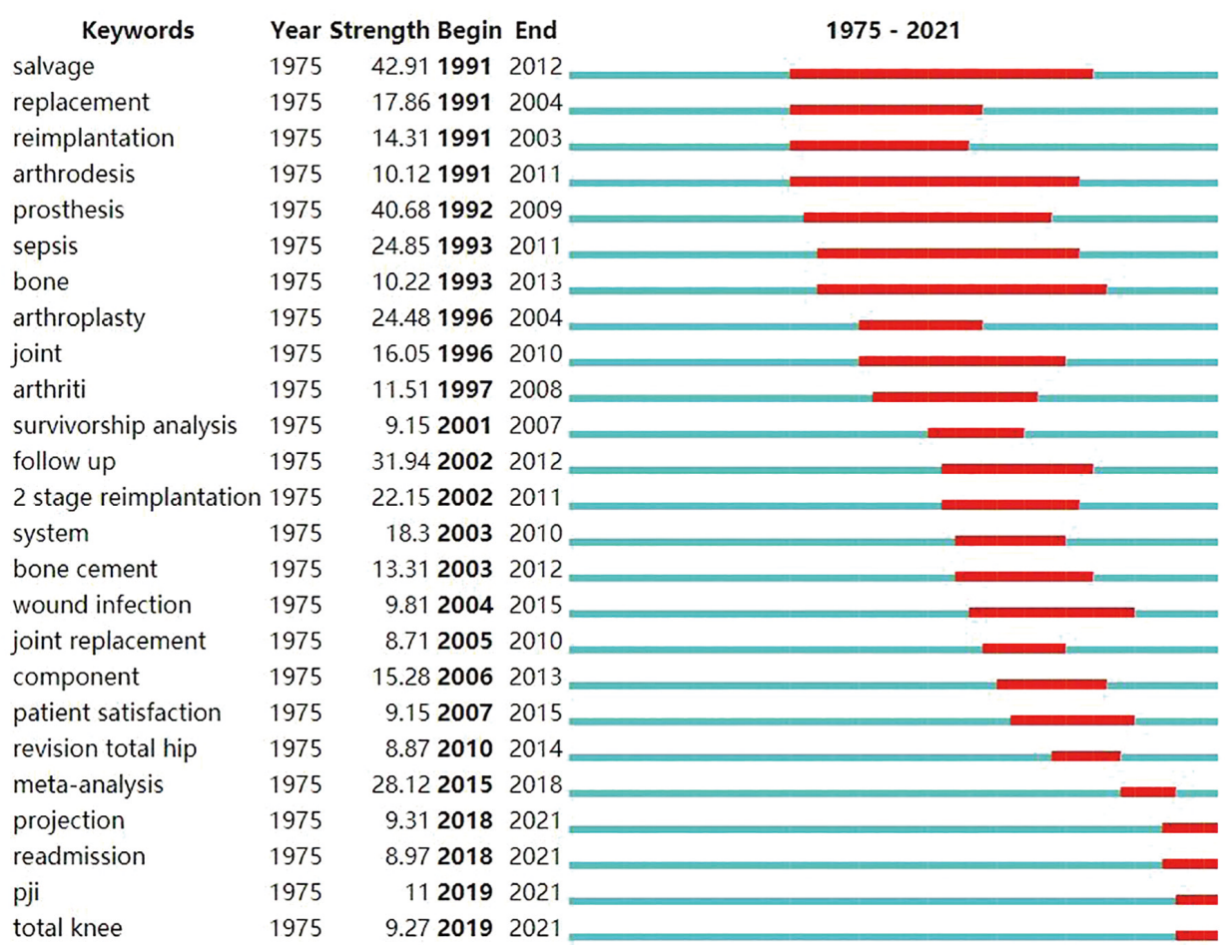

Figure 8 Top 25 keywords with the strongest citation bursts.

antibiotics based on the drug resistance of the pathogen (a combination of four antibiotics is recommended), and the use duration should be at least 6 months (7). The first choice for the treatment of fungal infections is the secondstage revision. Antifungal drugs should be used for no less than 6 weeks between revisions, and antifungal drugs should be taken orally for 3 to 6 months after revision, while for patients who cannot tolerate surgery or whose function cannot improve, or those who refuse surgery, longterm oral antibiotics instead of surgery can be considered $(7,26)$. In addition to drug anti-infective treatment, some patients require surgery (27). Surgery is recommended for acute infection with prosthesis preservation debridement, and chronic infection with secondary revision $(7,28)$. While knee fusion may also allow for limb salvage, it sacrifices the function of the knee joint and can only be used as an adjuvant treatment for infection control (7).

This study showed an overview of related research on infection after TKA. The results of this analysis suggests that while there are many countries and institutions participating in the research on this topic, and cooperation between countries and institutions is extensive, as mentioned earlier, there is a lack of high-level evidence. Keyword analysis results show that the focus of research in recent years has not changed significantly, suggesting there have been no significant breakthroughs in prevention and treatment. Therefore, research in this field requires further in-depth exploration, and should combine the latest basic scientific research results, artificial intelligence technology, and other measures, while designing more randomized controlled trials to provide stronger high-level evidence, which might be the focus of research in the future.

There are some limitations to this research. Firstly, the study employs descriptive research, only showing the current research situation in this field from a macro perspective, and it is impossible to conduct a detailed analysis of every document. Therefore, it is impossible to clearly analyze the specific links between the documents. In addition, due to the limitation of the search strategy, some documents may be missed. However, this also puts forward new requirements for the documentation of records, because, according to our analysis, the current use of keywords and subject terms is quite confusing. There may be multiple ways of expressing the same meaning, resulting 
in the irregular use of subject terms and keywords, which brings difficulties to comprehensive bibliometric analysis.

\section{Acknowledgments}

Funding: None.

\section{Footnote}

Conflicts of Interest: All authors have completed the ICMJE uniform disclosure form (available at https://dx.doi. org/10.21037/apm-21-2278). The authors have no conflicts of interest to declare.

Ethical Statement: The authors are accountable for all aspects of the work in ensuring that questions related to the accuracy or integrity of any part of the work are appropriately investigated and resolved.

Open Access Statement: This is an Open Access article distributed in accordance with the Creative Commons Attribution-NonCommercial-NoDerivs 4.0 International License (CC BY-NC-ND 4.0), which permits the noncommercial replication and distribution of the article with the strict proviso that no changes or edits are made and the original work is properly cited (including links to both the formal publication through the relevant DOI and the license). See: https://creativecommons.org/licenses/by-nc-nd/4.0/.

\section{References}

1. Price AJ, Alvand A, Troelsen A, et al. Knee replacement. Lancet 2018;392:1672-82.

2. Remily EA, Mohamed NS, Wilkie WA, et al. Obesity and its effect on outcomes in same-day bilateral total knee arthroplasty. Ann Transl Med 2020;8:936.

3. Mihalko WM, Manaswi A, Brown TE, et al. Infection in primary total knee arthroplasty: contributing factors. Instr Course Lect 2008;57:317-25.

4. DeRogatis MJ, Mahon AM, Lee P, et al. Perioperative Considerations to Reduce Infection Risk in Primary Total Hip and Knee Arthroplasty. JBJS Rev 2018;6:e8.

5. Koh CK, Zeng I, Ravi S, et al. Periprosthetic Joint Infection Is the Main Cause of Failure for Modern Knee Arthroplasty: An Analysis of 11,134 Knees. Clin Orthop Relat Res 2017;475:2194-201.

6. Jenny JY. Specificities of total hip and knee arthroplasty revision for infection. Orthop Traumatol Surg Res
2020;106:S27-34.

7. Abouljoud MM, Backstein D, Battenberg A, et al. Hip and Knee Section, Treatment, Surgical Technique: Proceedings of International Consensus on Orthopedic Infections. J Arthroplasty 2019;34:S445-51.

8. Beam E, Osmon D. Prosthetic Joint Infection Update. Infect Dis Clin North Am 2018;32:843-59.

9. Blanco JF, Díaz A, Melchor FR, et al. Risk factors for periprosthetic joint infection after total knee arthroplasty. Arch Orthop Trauma Surg 2020;140:239-45.

10. Cooper ID. Bibliometrics basics. J Med Libr Assoc 2015;103:217-8.

11. Li C, Ojeda-Thies C, Xu C, et al. Meta-analysis in periprosthetic joint infection: a global bibliometric analysis. J Orthop Surg Res 2020;15:251.

12. Vina ER, Kwoh CK. Epidemiology of osteoarthritis: literature update. Curr Opin Rheumatol 2018;30:160-7.

13. Roos EM, Arden NK. Strategies for the prevention of knee osteoarthritis. Nat Rev Rheumatol 2016;12:92-101.

14. Kolasinski SL, Neogi T, Hochberg MC, et al. 2019 American College of Rheumatology/Arthritis Foundation Guideline for the Management of Osteoarthritis of the Hand, Hip, and Knee. Arthritis Care Res (Hoboken) 2020;72:149-62.

15. Cancienne JM, Werner BC, Browne JA. Is There a Threshold Value of Hemoglobin A1c That Predicts Risk of Infection Following Primary Total Hip Arthroplasty? J Arthroplasty 2017;32:S236-40.

16. Tarabichi M, Shohat N, Kheir MM, et al. Determining the Threshold for HbA1c as a Predictor for Adverse Outcomes After Total Joint Arthroplasty: A Multicenter, Retrospective Study. J Arthroplasty 2017;32:S263-S7.e1.

17. Golladay GJ, Satpathy J, Jiranek WA. Patient Optimization-Strategies That Work: Malnutrition. J Arthroplasty 2016;31:1631-4.

18. Peel TN, Dowsey MM, Buising KL, et al. Chlorhexidinealcohol versus iodine-alcohol for surgical site skin preparation in an elective arthroplasty (ACAISA) study: a cluster randomized controlled trial. Clin Microbiol Infect 2019;25:1239-45.

19. Peel TN, Watson E, Lee SJ. Randomised Controlled Trials of Alcohol-Based Surgical Site Skin Preparation for the Prevention of Surgical Site Infections: Systematic Review and Meta-Analysis. J Clin Med 2021;10:663.

20. Morrison TN, Chen AF, Taneja M, et al. Single vs Repeat Surgical Skin Preparations for Reducing Surgical Site Infection After Total Joint Arthroplasty: A Prospective, Randomized, Double-Blinded Study. J Arthroplasty 
2016;31:1289-94.

21. Gallo J, Nieslanikova E. Prevention of Prosthetic Joint Infection: From Traditional Approaches towards Quality Improvement and Data Mining. J Clin Med 2020;9:2190.

22. AlBuhairan B, Hind D, Hutchinson A. Antibiotic prophylaxis for wound infections in total joint arthroplasty: a systematic review. J Bone Joint Surg Br 2008;90:915-9.

23. Siddiqi A, Forte SA, Docter S, et al. Perioperative Antibiotic Prophylaxis in Total Joint Arthroplasty: A Systematic Review and Meta-Analysis. J Bone Joint Surg Am 2019;101:828-42.

24. Dombrowski ME, Klatt BA, Deirmengian CA, et al. Musculoskeletal Infection Society (MSIS) Update on Infection in Arthroplasty. Instr Course Lect 2020;69:85-102.

25. Vadiee I, Backstein DJ. The Effectiveness of Repeat
Two-Stage Revision for the Treatment of Recalcitrant Total Knee Arthroplasty Infection. J Arthroplasty 2019;34:369-74.

26. Ahmed SS, Begum F, Kayani B, et al. Risk factors, diagnosis and management of prosthetic joint infection after total hip arthroplasty. Expert Rev Med Devices 2019;16:1063-70.

27. Lu J, Han J, Zhang C, et al. Infection after total knee arthroplasty and its gold standard surgical treatment: Spacers used in two-stage revision arthroplasty. Intractable Rare Dis Res 2017;6:256-61.

28. Gehrke T, Alijanipour P, Parvizi J. The management of an infected total knee arthroplasty. Bone Joint J 2015;97-B:20-9.

(English Language Editor: B. Draper)
Cite this article as: Shen S, Zhang Y, Zhang Q, Xiao K, Tang J. Periprosthetic joint infection after total knee arthroplasty: a bibliometrics analysis. Ann Palliat Med 2021;10(9):9927-9939. doi: 10.21037/apm-21-2278 